\title{
La distribución de excedentes en la legislación argentina de cooperativas y sus implicancias tributarias
}

The distribution of surpluses in legislation Argentina of cooperatives and its tax implications

\section{A distribuição de excedentes na legislação argentina de cooperativas e suas implicações tributárias}

\section{Dante Cracogna}

\author{
Recibido: 29 de junio de 2018 \\ Aceptado: 19 de septiembre del 2018 \\ Publicado: 10 de enero de 2019 \\ Cómo citar este artículo: \\ Cracogna, D. (2019). La distribución de excedentes en la legislación argentina \\ de cooperativas y sus implicancias tributarias. \\ Cooperativismo \& Desarrollo, 27(1). 1 - 19. \\ DOI: https://doi.org/10.16925/2382-4220.2019.01.03
}

Artículo de reflexión. https://doi.org/10.16925/2382-4220.2019.01.03

* Universidad de Buenos Aires, Buenos Aires, Argentina. ORCID: 0000-0001-7315-8704

Correo electrónico: dantecracogna@derecho.uba.ar 


\section{Resumen}

Objetivo: a propósito de un proyecto de reforma impositiva, que finalmente no prosperó, orientado a gravar los excedentes de las cooperativas con el impuesto a las ganancias, el artículo analiza la naturaleza de tales excedentes en la legislación argentina para fundamentar su no sujeción al tributo. Metodología: se examinan los distintos aspectos legales que diferencian a los excedentes de las cooperativas de las ganancias de las sociedades en general. Resultados: a la luz de la normativa vigente, se deslinda y caracteriza la naturaleza peculiar de las cooperativas analizando el mecanismo que la ley impone para la determinación de los excedentes y el procedimiento para su reparto, así como las características propias del capital cooperativo y la forma de su retribución, la devolución a los asociados en caso de retiro y de disolución, y la constitución de las reservas de naturaleza irrepartible. Discusión y conclusiones: se señala que, en definitiva, los asociados individualmente se hallan sujetos al gravamen. Concluye advirtiendo los crecientes riesgos que enfrentan las cooperativas en esta materia derivados tanto de su confusión con las sociedades lucrativas, como de las siempre crecientes necesidades fiscales.

Palabras clave: capital cooperativo, cooperativas, excedentes, impuestos, reservas, retornos.

\section{Summary}

Objective: about a project of tax reform, which finally did not prosper, aimed at taxing the surplus of the cooperatives with the income tax, the article analyzes the nature of such surpluses in the Argentine legislation to support its non-subjection to the tax. Methodology: the different legal aspects that differentiate the surpluses of the cooperatives from the earnings of societies in general. Results: in light of current regulations, the peculiar nature of cooperatives is defined and characterized by analyzing the mechanism that the law imposes for the determination of surpluses and the procedure for their distribution, as well As the characteristics of the cooperative capital and the form of its remuneration, the return to the associates in case of withdrawal and dissolution, and the constitution of reserves of an irreparable nature. Discussion and conclusions: it is pointed out that, ultimately, the associates individually are subject to the tax. Concludes by noting the growing risks that cooperatives face in this matter derived from their confusion with lucrative societies, as of ever increasing fiscal needs.

Keywords: cooperative capital, cooperatives, surpluses, taxes, reserves, returns.

\section{Resumo}

Objetivo: a propósito de um projeto de reforma impositiva, que finalmente não prosperou, orientado a tributar os excedentes das cooperativas com um imposto sobre o rendimento, o artigo analisa a natureza de tais excedentes na legislação argentina para fundamentar sua sujeição ao tributo. Metodologia: examinam-se os diferentes aspectos legais que diferenciam os excedentes das cooperativas dos rendimentos das sociedades em geral. Resultados: à luz da normativa vigente, deslinda-se e caracteriza-se a natureza peculiar das cooperativas e analisa-se o mecanismo que a lei impõe para a determinação dos excedentes e o procedimento para sua divisão, bem como as características próprias do capital cooperativo e da forma de retribuição, a devolução aos associados em caso de saída e de dissolução, e a constituição das reservas de natureza indivisível. Discussão e conclusões: assinala-se que, definitivamente, os associados individualmente estão sujeitos à tributação. Conclui-se com uma advertência aos crescentes riscos que as cooperativas enfrentam nessa matéria, derivados tanto de sua confusão com as sociedades lucrativas quanto das sempre crescentes necessidades fiscais.

Palavras-chave: capital cooperativo, cooperativas, excedentes, impostos, reservas, retornos. 


\section{Introducción}

En los últimos meses del 2017, el Gobierno nacional argentino remitió al Congreso un amplio proyecto de ley de reforma tributaria que abarca diferentes impuestos que, junto con una modificación del régimen previsional y de la legislación laboral, constituye un paquete legislativo diseñado para promover el crecimiento de la economía, estancada durante los últimos años.

En materia de impuesto a las ganancias - antes denominado impuesto a los réditos ${ }^{-}$, el régimen fiscal vigente desde hace muchos años establece que están exentas del gravamen: "Las utilidades de las sociedades cooperativas de cualquier naturaleza y las que bajo cualquier denominación (retorno, interés accionario, etc.), distribuyen las cooperativas de consumo entre sus socios" (art. 20, inc. d, Ley de Impuesto a las Ganancias).

A su vez, los asociados ${ }^{2}$ de las cooperativas deben incluir los retornos e intereses que perciban en sus respectivas declaraciones de impuestos y tributar por ellos, puesto que no se hallan exentos, salvo en las cooperativas de consumo; esto se diferencia de lo que sucede con las sociedades de capital, que tienen gravadas las ganancias que distribuyen pero sobre las cuales no tributan los socios que las perciben.

El mencionado proyecto de reforma incorporaba un párrafo al referido art. 20, inc. d, estableciendo que la aludida exención "no será de aplicación a los resultados provenientes de actividades de ahorro, crédito y/o financieras o de seguros y reaseguros [...]". De tal manera, un sector de cooperativas quedaba privado de la exención, siendo destacable que la eliminación de la exención no tenía alcances precisos, toda vez que "actividades de crédito" pueden realizar tanto las cooperativas que se dedican específicamente a esa actividad (bancos y cooperativas de crédito), como las de otra actividad pero que cuentan con una sección dedicada a ella, y aun las de cualquier otro objeto social que brindan financiamiento a sus asociados. Esto último sucede, por ejemplo, con las cooperativas agrarias que proveen insumos a sus asociados para ser pagados en el momento de la cosecha; o con las de consumo que financian la adquisición de artículos para el hogar; o las de vivienda que otorgan crédito para su compra; etc.

1 Es evidente que la determinación del ámbito del gravamen o "hecho imponible" corresponde a la ley (principio de legalidad de los impuestos) y, en consecuencia, la ley respectiva puede establecer su propia definición de los términos "renta", "rédito", "ganancia", etc. Sin embargo, la ley no podría dar a tales vocablos un significado ajeno a su sentido común o contradictorio a él so pena de incurrir en arbitrariedad.

2 Corresponde aclarar que La Ley de Cooperativas 20.337 (LC) llama "asociados" a los miembros integrantes de las cooperativas, que en otras legislaciones suelen denominarse "socios". 
Por otra parte, los fundamentos con los que el poder ejecutivo acompañó el proyecto no abundan en razones que explicaran el porqué de la reforma a una normativa vigente durante largo tiempo, limitándose a expresar que su finalidad era "dotar de mayor equidad al sistema tributario", expresión de una latitud muy extensa y controvertible.

Obviamente, la eliminación de la exención con tan escuetos fundamentos podría alcanzar a toda clase de cooperativas, no solo a las de crédito y seguros, lo cual resultaba previsible que sucediera en cualquier momento a partir de la aprobación de la reforma.

La cuestión a analizar consiste en la procedencia de someter a las cooperativas al impuesto a las ganancias para lo cual resulta necesario determinar la naturaleza de los excedentes que ellas producen y su forma de distribución ${ }^{3}$.

\section{Características de la Ley de Cooperativas (LC)}

La LC no contiene disposiciones en materia tributaria; tampoco existe una ley general de régimen fiscal de las cooperativas, como sucede en otros países ${ }^{4}$. Por lo tanto, el tratamiento fiscal de las cooperativas debe buscarse en las distintas leyes que regulan los diferentes impuestos en el orden nacional -impuesto a las ganancias, al valor agregado, a las operaciones bancarias, internos, entre otros-. Así mismo, teniendo en cuenta la organización federal del país, el panorama fiscal ha de completarse con las normas impositivas provinciales -impuestos a los ingresos brutos, de sellos, inmobiliario, a los automotores, entre otros-y, en última instancia, con las normas de nivel municipal (diversas tasas que por lo general cubren los servicios de los municipios). Todo ello resulta en un variado y complejo sistema.

La LC es de carácter general, vale decir que regula toda clase de cooperativas existentes en todo el territorio nacional, cualquiera sea su objeto social específico, por lo que las consideraciones sobre el tema del impuesto a las ganancias resultan aplicables su conjunto.

Por otra parte, cabe señalar que la terminología que emplea la LC transcribe apego estricto a la naturaleza propia de las cooperativas, a diferencia de lo que ocurre con la legislación impositiva que la ignora por completo y se limita a utilizar

3 No se tratan otros impuestos, pues el estudio se circunscribe a la proyectada reforma del impuesto a las ganancias. Sin embargo, en el régimen fiscal argentino estar gravado con este tributo puede incidir en que se deba pagar o no algún otro impuesto.

4 Tal es el caso del régimen estatal español (Aguilar, 2015, p. 380). 
el vocabulario de las sociedades de capital con carácter general. Esto último suele inducir a confusión.

\section{La cooperativa en el marco de las personas jurídicas privadas}

Durante la vigencia de la anterior ley de cooperativas ${ }^{5}$, se discutía si estas eran sociedades o asociaciones, y en el primer caso, si eran civiles o comerciales. En general, prevalecía la tesis de que eran sociedades comerciales en virtud de hallarse dicha ley incluida en el Código de Comercio y aplicárseles supletoriamente las normas sobre sociedades anónimas.

Con la sanción de la Ley 20.337, el panorama cambió notablemente: la actual LC no fue incorporada al Código de Comercio y la aplicación supletoria de las disposiciones sobre sociedades anónimas quedó circunscrita a los casos en que ellas se concilien con las de la LC y la naturaleza de las cooperativas (art. 118). Además, el art. 6 de la LC estableció categóricamente que las cooperativas: "No pueden transformarse en sociedades comerciales o asociaciones civiles. Es nula toda resolución en contrario". Con esta disposición, quedó definitivamente claro que no son sociedades ni asociaciones; y actualmente no son sociedades comerciales ni civiles, pues la ley que sancionó el Código Civil y Comercial vigente desde el 2015 eliminó a estas últimas unificando el régimen de todas ellas en la Ley General de Sociedades $19.550^{6}$.

El art. 148 del Código Civil y Comercial cuando enumera a las personas jurídicas privadas, separa a las cooperativas de las sociedades y también de las asociaciones (Cracogna, 2015a). De tal suerte que no quedan ya dudas acerca de la naturaleza particular de las cooperativas cuya ley, por otra parte, es respetuosa de los principios universales del cooperativismo?.

5 La anterior Ley de Cooperativas (11.388) fue sancionada en 1926 y rigió hasta 1973, año en que fue sustituida por la actual Ley 20.337.

6 Actualmente solo existen "sociedades" regidas por la Ley General de Sociedades 19.550, antes denominada Ley de Sociedades Comerciales.

7 Si bien la Lc fue sancionada antes de la Declaración sobre la Identidad Cooperativa aprobada por la Alianza Cooperativa Internacional en el Congreso del Centenario realizado en 1995, su contenido sigue los principios cooperativos proclamados por la ACl en el Congreso de Viena de 1966 que no tienen sustancial diferencia con los de 1995. 


\section{Excedentes repartibles}

El artículo 42 de la LC, primer párrafo, define los excedentes repartibles como "aquellos que provengan de la diferencia entre el precio y el costo del servicio prestado a los asociados". De esta definición corresponde destacar las siguientes notas:

a) se circunscribe al excedente repartible, es decir a aquel que puede distribuirse puesto que existen otros excedente no repartibles;

b) la noción se refiere a la diferencia entre costo y precio del servicio, por lo que no incluye excedentes que provengan de otras fuentes; se trata solamente de la diferencia surgida de las operaciones realizadas en cumplimiento del objeto social, es decir el servicio previsto en el estatuto de la cooperativa;

c) la diferencia que constituye el excedente debe provenir del servicio prestado a los asociados, de tal suerte que se excluyen las diferencias que provengan de servicios prestados a no asociados.

De manera que la fuente del excedente repartible es exclusivamente la prestación de servicios a los asociados. Esto significa que el excedente proviene de habérsele cobrado el servicio al asociado por encima del costo en el caso de las cooperativas de distribución -consumo, provisión, seguro, vivienda, crédito, entre otros- o de habérsele pagado menos de lo percibido en el caso de las cooperativas de mercadeo -agrícolas, artesanales, de producción, de trabajo, entre otros-. Sucede que en uno y otro caso la cooperativa realiza sus operaciones sobre la base de un precio estimado que cobra o paga a los asociados durante el transcurso del ejercicio, toda vez que no puede calcular para cada una de ellas el precio exacto y definitivo, pues existen rubros cuyo importe solamente se conoce con precisión al finalizar el ejercicio y confeccionar el balance general. Es en ese momento cuando la diferencia entre costo y precio del servicio resulta susceptible de determinarse de manera final; allí, entonces, puede fijarse el excedente repartible ${ }^{8}$.

Por lo dicho, la noción de excedente repartible es crucial para analizar la procedencia de gravarlo con el impuesto a las ganancias.

\section{La distribución del excedente. Reserva y fondos}

Una vez determinado el excedente repartible al finalizar el ejercicio, la LC (art. 42) impone destinarlo de la siguiente forma:

8 Sobre el tema, con especial referencia a los aspectos contables involucrados, consultar Cracogna (s. f., p. 617). 
a) $5 \%$ a reserva legal que se va incrementando anualmente, sin límite, a diferencia de lo que sucede en las sociedades ${ }^{9}$. Por consiguiente, en las cooperativas puede suceder que la reserva legal llegue a superar el capital social. Por otra parte, como medida adicional de protección del capital, la LC determina que cuando se hayan utilizado reservas para compensar quebrantos, no se podrán distribuir excedentes hasta haberlas recompuesto al nivel anterior a su utilización (art. 43).

b) $5 \%$ al fondo de acción asistencial y laboral o para estímulo del personal. Este destino es una singularidad de las cooperativas, pues no existe otra forma societaria o asociativa que lo tenga legalmente establecido. Se trata de un reconocimiento al personal por su colaboración en la formación del resultado y afianza el sentido social de la cooperativa. La LC no establece pautas precisas para su asignación, pero es claro el sentido de beneficiar a los trabajadores, sea en dinero o en servicios. La autoridad de aplicación ha dictado una resolución orientativa acerca de la aplicación de este fondo procurando su efectiva y oportuna utilización ${ }^{10}$.

c) $5 \%$ al fondo de educación y capacitación de cooperativas. Esta norma se compadece con el principio cooperativo de fomento de la educación, asignando recursos específicos a tal efecto. Como complemento, la LC obliga a invertir anualmente dicho fondo ya sea en forma directa o a través de una entidad de grado superior o de una institución especializada con personería jurídica (art. 46), y obliga a informar en la memoria acerca de su utilización (art. 40, inc. 3). También acerca de este tema dictó resolución la autoridad de aplicación ${ }^{11}$.

\section{El capital y su retribución}

La cooperativa es una empresa, pues organiza y coordina factores de la producción para realizar la actividad que constituye su objeto social. Entre dichos factores se encuentra el capital y la LC dota al capital cooperativo de una regulación específica: es ilimitado y variable (art. 2, incs. 1 y 2), y se divide en cuotas sociales de igual valor que

9 En las sociedades anónimas y de responsabilidad limitada, la reserva legal debe constituirse a razón del $5 \%$ de las ganancias realizadas y líquidas hasta alcanzar el $20 \%$ del capital social (art. 70, Ley 19.550).

10 La Res. ex INAC 177/83 estableció la obligación de aplicar el fondo en el ejercicio inmediato siguiente al que lo originó e informar acerca de su empleo en la memoria respectiva.

11 La Res. ex SAC 577/84 y sus modificatorias realizan una enumeración no limitativa de posibles destinos concretos para la aplicación de este fondo. 
se representan en acciones nominativas que solo son transferibles entre asociados con acuerdo del consejo de administración (art. 24).

Ese capital aportado por los asociados puede o no ser retribuido, conforme lo determine el estatuto. En caso afirmativo, dicha retribución se halla supeditada a la existencia de excedentes y no puede superar en más de un punto la tasa que cobra el Banco de la Nación Argentina en sus operaciones de descuento (art. 42, inc. 4$, LC $)^{12}$. De manera que, en todo caso, el capital aportado por los asociados como condición para ingresar a formar parte de la cooperativa, o bien ampliado durante su permanencia en ella, solamente puede ser retribuido con una tasa fijada por la asamblea dentro del límite establecido por la LC; y ello siempre que el estatuto lo autorice. Queda claro, pues, que no puede existir inversión especulativa o de lucro y que el capital no puede apropiarse en forma ilimitada del resultado de la actividad de la cooperativa. Tampoco puede existir capital aportado por socios inversores, como admiten algunas legislaciones ${ }^{13}$.

Cuando un asociado se retira de la cooperativa por cualquier causa, solo tiene derecho a que se le reembolse el valor nominal de las cuotas sociales integradas, y si existieran pérdidas, debe deducirse de ese importe la parte que proporcionalmente le correspondiera soportar (art. 36, LC). De igual manera, en caso de disolución, una vez pagadas las deudas, solo se le devolverá a cada asociado el valor nominal de sus cuotas sociales integradas (art. 95, segundo párrafo, LC), ya que el resto pasará al Fisco.

Por otro lado, ratificando la condición subordinada del capital, la LC establece que todos los asociados cuentan con un solo voto, cualquiera sea el número de sus cuotas sociales, y que no se puede conceder ventaja ni privilegio alguno a los iniciadores o fundadores, ni preferencia a parte alguna del capital (art. 2, inc. 3). No existe el voto múltiple en ningún supuesto, salvo en las cooperativas de grado superior (federaciones y confederaciones), pero sin relación con el capital y sujeto a limitaciones que aseguren la participación de todas las asociadas y que impidan el predominio de alguna de ellas (art. 85, LC) $)^{14}$.

12 Cabe señalar que el Banco de la Nación Argentina es un banco oficial que realiza actividades financieras comerciales y sus tasas suelen utilizarse como referencia para diferentes operaciones.

13 La modalidad de socios inversores comenzó en la década de 1990 en Bélgica, Italia y Francia, y se extendió luego a otros países con distintas variantes, pero con el rasgo común de tratarse de socios que solo aportan capital, sin utilizar los servicios de la cooperativa, a los que se les reconoce una participación limitada en los órganos sociales.

14 La doctrina destaca que los distintos sistemas de representación y voto en las cooperativas de grado superior no admiten la proporcionalidad con las cuotas sociales aportadas (Althaus, 1977, p. 450). 


\section{Retorno a las operaciones}

El resto del excedente - una vez deducidos la reserva legal, los fondos de acción asistencial y de educación y el interés al capital si el estatuto lo previera- debe distribuirse entre los asociados en concepto de retorno, en proporción a las operaciones realizadas por cada uno de ellos con la cooperativa durante el ejercicio. Aquí radica la diferencia sustancial de las cooperativas con respecto a las sociedades de capital: en estas últimas la ganancia -lucro, utilidad, beneficio- consiste en la diferencia entre el costo y el precio de los bienes o servicios que proveen a los terceros ajenos a ellas valiéndose de la inversión realizada por sus socios y por eso se reparte en proporción al capital aportado por cada uno.

En cambio, en la cooperativa el excedente lo generan los propios asociados mediante su operatoria con ella. Por lo tanto, cada asociado recibe una parte del excedente en medida estrictamente proporcional a su contribución: el que más utilizó los servicios de la cooperativa más recibe puesto que el excedente deriva de lo que pagó de más o de lo que cobró de menos durante el ejercicio. Como es fácil advertir, no existe lucro a expensas de terceros, sino simplemente ajuste del precio que cada asociado haya pagado o percibido durante el ejercicio ${ }^{15}$.

Esta singular operatoria constituye una relación jurídica peculiar que la LC (art. 4) denomina acto cooperativo, puesto que tiene la característica de realizarse entre la cooperativa y sus asociados en el cumplimiento del objeto social teniendo como fin el servicio. Dicha relación se rige por la LC, los estatutos y reglamentos, y supletoriamente por las disposiciones de los institutos jurídicos que guardan afinidad con el contenido del acto ${ }^{16}$.

Siguiendo la técnica de la anterior ley de cooperativas, el art. 42, inc. 5, de la LC contiene una ejemplificación de cómo debe realizarse la distribución de los retornos en diferentes clases de cooperativas -consumo, trabajo, provisión, comercialización, industrialización, crédito-. Empero, la regla general está contenida en el último párrafo del citado inc. 5 cuando prescribe que en las demás cooperativas se efectuará "en proporción a las operaciones realizadas o a los servicios utilizados por cada asociado". Queda así evidenciado que el retorno, como su denominación indica, consiste

15 La devolución de los excedentes en proporción a las operaciones o retorno, conocido como principio de Howarth en honor de quien lo introdujo en la Cooperativa de Rochdale, constituye la piedra de toque que diferencia a la cooperativa de las sociedades de capital. Holyoake (2016, p. 23) señala, sin embargo, que el primero en descubrir este principio fue Alexander Campbell, de Glasgow, quien lo introdujo en el estatuto de la Sociedad de Cambuslang.

16 Acerca del acto cooperativo existe una extensa producción. Para una visión sintética, puede consultarse Cracogna (1986, p. 13) y Cracogna (2004, p. 45), trabajos que refieren varios casos jurisprudenciales que tratan sobre la materia. 
en la devolución del resultado que se efectúa a los asociados como ajuste del precio pagado por el servicio durante el ejercicio.

Caso especial que merece aclaración es el de las cooperativas o secciones de crédito, en las que la LC admite que el retorno se distribuya "en proporción al capital aportado o a los servicios utilizados, según establezca el estatuto" (art. 42, inc. 5, ap. d). Esta variante se explica en función de estimular el ahorro popular mediante la capitalización de estas cooperativas que, por lo común, nuclean a sectores de menores recursos. De todas maneras, queda librado a la voluntad de los asociados decidir en cada cooperativa qué variante adoptar para la distribución de los retornos.

\section{Seccionalización de resultados}

La experiencia nacional ha demostrado que numerosas cooperativas nacen para atender varias necesidades de sus asociados: por ejemplo, las cooperativas agrarias se proponen, simultáneamente, proveer insumos a sus asociados y comercializar sus cosechas, o bien surgen para atender un servicio y luego van incorporando otros, como sucede con las cooperativas de servicios públicos que comienzan distribuyendo energía eléctrica y después suministran gas o agua o proveen telefonía o internet, etc. En tales casos, los servicios se organizan por secciones en razón de sus características técnicas y económicas, aunque con una única estructura empresarial ${ }^{17}$.

Para los supuestos de cooperativas de servicios múltiples, la Lc establece que los resultados deben determinarse por secciones (art. 43), lo cual resulta lógico pues cada asociado contribuyó a formar el resultado según las secciones -una o másen las que hubiera operado; es decir, se trata de una regla de equidad. No obstante, como la cooperativa constituye una unidad patrimonial, la aludida norma dispone que no podrán distribuirse excedentes de una sección sin compensar previamente los quebrantos de las secciones que hubieran arrojado pérdida. De tal suerte, los asociados percibirán los retornos que a su operatoria en cada sección correspondan, pero previamente se consolidarán los resultados generales de la cooperativa, absorbiendo cada sección los quebrantos de las otras en forma proporcional.

17 Sin embargo, existen disposiciones legales que obligan que determinados servicios sean prestados por una entidad en forma exclusiva; así sucede con el seguro y la banca (Leyes 20.091 y 21.526 , respectivamente). 


\section{Operaciones con no asociados}

La LC permite que las cooperativas presten servicios a no asociados en las condiciones que establezca la autoridad de aplicación (art. 2, inc. 10), pero supedita este permiso a una estricta condición: "Los excedentes que deriven de la prestación de servicios a no asociados autorizada por esta ley se destinarán a una cuenta especial de reserva" (art. 42, último párrafo).

En esta norma, reside una característica fundamental de las cooperativas: no pueden distribuir excedentes provenientes de operaciones con no asociados, aunque deben -obviamente- absorber los quebrantos que ellas pudieran arrojar. En suma, los asociados no pueden lucrarse a costa de los no asociados.

La exigencia de destinar tales excedentes a una cuenta especial de reserva implica contabilizar separadamente las operaciones con no asociados y que la reserva así constituida permanezca indefinidamente en el patrimonio de la cooperativa, puesto que participa del carácter irrepartible que la LC asigna a las reservas en general. De tal suerte, ni aun en caso de disolución podrán los asociados apropiarse de ellas, pues deben pasar al Fisco (arts. 95 y 101, LC).

En consecuencia, esta operatoria puede interpretarse como un servicio social que la cooperativa brinda a la comunidad, ya que los no asociados reciben el servicio sin aportar capital ni soportar los quebrantos que ella pudiera producir.

\section{Régimen de las reservas}

La LC es categórica en cuanto a la irrepartibilidad de las reservas. Así lo consagra el art. 2, inc. 12 al enumerar los rasgos que caracterizan a las cooperativas. No pueden repartirse ni capitalizarse; deben permanecer identificadas como tales en el grupo de las cuentas que integran el patrimonio social (Farrés y Menéndez, 1987, p. 12).

Cuando se hayan utilizado reservas para compensar quebrantos, no se podrán distribuir excedentes sin haberlas reconstituido al nivel anterior a su utilización y tampoco podrán distribuirse excedentes sin haber compensado las pérdidas de ejercicios anteriores (art. 43, LC).

Además de la reserva legal, participa del mismo carácter irrepartible la reserva especial formada con los excedentes producidos por las operaciones realizadas con no asociados (art. 42, in fine, LC). Esta reserva también se va acumulando en forma indefinida, al igual que la que surge de excedentes producidos por operaciones no estrictamente derivadas del cumplimiento del objeto social, tales como la enajenación de bienes del activo fijo o auxilios económicos recibidos de terceros. 
Cuando un asociado se retira de la cooperativa por cualquier causa, sea en forma voluntaria o por exclusión, solo tiene derecho a que se le reembolse el valor nominal de las cuotas sociales integradas, vale decir con independencia de las reservas acumuladas o del mayor valor patrimonial de la cooperativa. Empero, si existieran pérdidas, se debe deducir de dicho valor el importe que proporcionalmente le correspondiera soportar conforme a su capital suscripto (art. 36, LC).

En caso de disolución, una vez realizado el activo y satisfecho el pasivo se reembolsará a los asociados el valor nominal de sus cuotas sociales. En este caso, también se deducirá la parte proporcional de los quebrantos, si los hubiera; es decir que el valor nominal de las cuotas sociales será el importe máximo que los asociados podrán percibir en la liquidación (art. 94, último párrafo, LC). Queda clara la diferencia con las sociedades, en las cuales una vez concluida la liquidación la partición final del remanente tiene lugar en proporción al capital aportado por cada socio.

Por último, el sobrante patrimonial que pudiera resultar de la liquidación, es decir, el remanente total de los bienes sociales una vez pagadas las deudas y devuelto el valor nominal de las cuotas sociales debe entregarse al Fisco de la jurisdicción del domicilio de la cooperativa con destino a promoción del cooperativismo (arts. 95 y 101, último párrafo, LC). De manera que, en última instancia, el Estado tiene un derecho en expectativa sobre las reservas acumuladas por las cooperativas a lo largo de su existencia, el cual se materializa al finalizar su liquidación.

\section{Forma de pago de intereses y retornos}

La LC determina de manera precisa cuál es el excedente repartible y su destino. La forma de pago queda librada a lo que cada cooperativa resuelva según su organización y actividades: pago en efectivo, acreditación en cuenta del asociado en la propia cooperativa, crédito para adquisición de bienes o servicios, acreditación en cuenta bancaria, etc.

Sin embargo, la LC contiene la expresa permisión de que la asamblea resuelva que los intereses - caso de estar previstos en el estatuto- y los retornos sean distribuidos total o parcialmente en cuotas sociales (art. 44). Esta autorización vino a despejar una vieja controversia acerca de si la asamblea tenía competencia para decidir en materia del derecho de los asociados a disponer sobre sus créditos individuales ${ }^{18}$. Por otro lado, contribuyó eficazmente a promover y facilitar la capitalización

18 Doctrinaria y jurisprudencialmente, se sostuvo que cada asociado tenía un derecho propio e individual sobre sus intereses y retornos a percibir, por lo cual no resultaba legalmente aceptable que la asamblea por mayoría resolviera acerca de cómo debía percibirlos. 
de las cooperativas, puesto que es conocida su dificultad para obtener capital de sus asociados debido a la estricta limitación del interés que puede pagarse. Es decir que esta norma facilita la reinversión de los excedentes contribuyendo a consolidar el patrimonio de la cooperativa, manteniendo los asociados la propiedad de tales importes $^{19}$. Desde el punto de vista fiscal, la reinversión en toda empresa constituye una conducta que generalmente es merecedora de estímulo.

\section{Absorción de pérdidas}

No existe norma expresa en la Lc relativa a la absorción de las pérdidas que la gestión de la cooperativa pudiera arrojar. No obstante, el art. 43 prohíbe distribuir excedentes sin previa compensación de quebrantos y agrega que cuando se hayan utilizado reservas para ese fin, deben ser reconstituidas a su nivel anterior antes de distribuir excedentes; de manera que admite que las reservas sean utilizadas para enjugar pérdidas.

Ahora bien, puede suceder que una vez agotadas las reservas todavía subsistan pérdidas y aunque para este supuesto tampoco contiene la LC una disposición específica, el art. 36 prescribe que en caso de retiro, exclusión o disolución, los asociados solo tienen derecho a que se les reembolse el valor nominal de sus cuotas sociales integradas "deducidas las pérdidas que proporcionalmente les correspondiera soportar". Va de suyo, entonces, que las pérdidas que subsistan una vez consumidas las reservas deben detraerse del capital. Disminuye el capital social y, correlativamente, mengua el valor real de las cuotas sociales.

Esta situación no causa en la cooperativa ninguna consecuencia particular, toda vez que su capital es variable (art. 2, inc. 1, LC), a diferencia de lo que sucede en las sociedades, pero puede provocar un estado de impotencia financiera que conduzca a recurrir al remedio concursal, es decir, a un acuerdo judicial o extrajudicial con sus acreedores o, eventualmente, a la quiebra. Esta última produce la disolución de la cooperativa (art. 86, inc. 3, LC) (Cracogna, 2015b, p. 17).

\section{Asociados y capital variables}

Conforme al art. 2, inc. 1 y 2, de la LC, las cooperativas tienen capital variable y no ponen límite al número de asociados. Por ende, toda persona humana o jurídica que

19 Es obvio que la capitalización del excedente constituye una fuente de autofinanciamiento de fácil acceso y costo económico, puesto que el interés a pagar por las cuotas sociales está legalmente limitado. 
reúna las condiciones estatutarias para ser asociado puede formar parte de la cooperativa, lo cual significa poner a su disposición la organización y prestación del servicio sin cobrar prima alguna por las cuotas sociales que suscriba para su ingreso como asociado. La LC determina que si el estatuto estableciera un derecho de ingreso, su importe no puede exceder el valor de una cuota social ni puede elevárselo a título de compensación por las reservas sociales (art. 18).

Así mismo, ese ingreso irrestricto implica que las cooperativas en ningún caso pueden convertirse en una limitación a la competencia puesto que sus puertas se hallan abiertas a todos los que quieran obtener sus servicios, en igualdad de condiciones con los asociados ya existentes. Por ello, las cooperativas no pueden transformarse en monopolios de los servicios que prestan y aun en el caso de monopolios naturales, como la distribución de electricidad por ejemplo, todos los usuarios que lo desean pueden convertirse en asociados y no solo utilizar los servicios, sino también participar en el gobierno de la cooperativa sobre la base de "un asociado un voto".

Igualmente, no es posible especular con la negociación de las cuotas sociales puesto que ellas siempre conservan solo su valor nominal y, por otra parte, cualquier interesado que reúna los requisitos estatutarios puede asociarse directamente a la cooperativa sin tener que adquirir cuotas sociales de un asociado.

\section{Las normas de contabilidad de las cooperativas}

El art. 39 de la LC dispone que la presentación de los estados contables de las cooperativas debe ajustarse a la reglamentación que dicte la autoridad de aplicación (INAES), salvo lo establecido por los regímenes legales específicos para determinadas actividades - casos de banca y seguros-.

En virtud de esa disposición, la autoridad de aplicación impuso como obligatorias para las cooperativas las normas profesionales de contabilidad contenidas en la Resolución Técnica N.․ 24 de la Federación Argentina de Consejos Profesionales de Ciencias Económicas, que es la organización gremial de la profesión contable encargada de dictar las normas técnicas respectivas ${ }^{20}$.

20 La Res. 247/09 del INAES expresa: "Apruébase como norma de aplicación obligatoria para las cooperativas, reglamentando el artículo 39 de la Ley $\mathrm{N}^{\circ}{ }^{\circ} 20.337$, las 'Normas profesionales: Aspectos particulares de exposición contable y procedimientos de auditoría para entes cooperativos', originada en la Federación Argentina de Consejos Profesionales de Ciencias Económicas y difundida como Resolución Técnica N. 24 (RT 24)". 


\section{La introducción de la referida Resolución Técnica expresa:}

Los entes cooperativos presentan, como rasgo específico de su naturaleza, la capacidad de transformar las condiciones y relaciones económicas y sociales de sus asociados, y por extensión, de la comunidad donde actúan. La actividad de los entes cooperativos se desarrolla en un marco jurídico propio, a partir de la caracterización doctrinaria y de la definición legal del acto cooperativo en virtud del cual, el importe percibido por cada operación o servicio utilizado es de carácter provisorio, sujeto a ajuste en relación con el costo definitivo de los mismos, determinado al cierre del ejercicio. Por su parte, en los limitados servicios u operaciones ofrecidas a no asociados, el destino final de los excedentes generados por los mismos, reviste el carácter de irrepartible, no retornando estos a los asociados. La necesidad de proveer un marco contable específico, como correlato de aquel encuadramiento doctrinario y jurídico, justifica el dictado de normas particulares de exposición contable y de auditoría para los entes cooperativos.

De tal suerte, las normas técnico-contables ratifican de manera categórica la peculiar naturaleza de la operatoria cooperativa que queda así plasmada en los estados contables ${ }^{21}$.

\section{Exención y no sujeción}

En la teoría tributaria, existen dos situaciones claramente diferenciadas: exención y no sujeción. La primera consiste en un tratamiento especial, diferencial, que se asigna a algún sujeto o actividad que, por determinado motivo, el régimen fiscal considera que no debe pagar cierto tributo, aun estando gravado; se le aplica un tratamiento excepcional que lo exime de la obligación impositiva. De no existir ese tratamiento favorable, ese sujeto o esa actividad deberían satisfacer el impuesto como los demás contribuyentes. Por otra parte, la exención puede ser dejada sin efecto cuando desaparecen o cambian las causas que la motivan o surgen otras que

21 De paso cabe apuntar que la Res. Técnica N. ${ }^{\circ} 24$ considera al capital como parte del patrimonio de la cooperativa, con lo que evita las negativas consecuencias que hubiera provocado la aplicación de las Normas Internacionales de Información Financiera (NIIF) que lo ubican dentro del pasivo. (Cracogna, 2012, p. 369). 
así lo aconsejen; todo según la voluntad discrecional del legislador. La no sujeción, en cambio, significa que determinado sujeto o actividad no se hallan gravados por cuanto no configuran el hecho imponible, es decir, no tributan por cuanto no existe en ellos la materia sujeta al gravamen.

Esta distinción, clara en la teoría, no siempre se traduce adecuadamente en la legislación de la materia en la cual con frecuencia existen situaciones confusas o promiscuas. Por lo tanto, se suelen encontrar casos llamados "de exención" cuando en realidad no existe hecho imponible; es decir, se trata de un caso de no sujeción. En tanto que otras veces se grava una actividad o sujeto a pesar de que no configuran el hecho imponible; es decir, no existe la materia que lo convierta en objeto de ese impuesto.

En el caso argentino, tradicionalmente la ley de impuesto a las ganancias - antes llamado impuesto a los réditos - ha dispensado a las cooperativas el tratamiento de exención, cuando en rigor ellas no configuran el hecho imponible. Más aún, se agrava la confusión al expresar el texto legal que se hallan exentas "las utilidades de las sociedades cooperativas" (resaltado añadido) puesto que, como se ha visto, no existen tales utilidades sino que se trata de un ajuste de precio que se devuelve a los asociados por vía del retorno. Y tampoco se trata de sociedades sino de entidades de naturaleza peculiar así reconocidas por su legislación específica y por el Código Civil y Comercial; en tanto que las sociedades tienen otro régimen legal y persiguen fin de lucro.

Esta promiscuidad terminológica -y conceptual- no ha provocado efectos prácticos negativos dado que, sea que se consideren exentas o no sujetas, el resultado es el mismo: las cooperativas no tributan el impuesto a las ganancias. Pero cuando el legislador decida modificar la situación, aparece entonces la diferencia: si se trata de exención, esta puede ser eliminada o reducida sin dificultad; en tanto que si se trata de no sujeción, no resulta posible imponer el gravamen.

\section{Tributación de los asociados}

Corresponde aclarar que si bien la inexistencia de lucro - ganancia- en la actividad cooperativa determina que no se configure el hecho imponible que grava el tributo analizado, ello no significa que en cabeza del asociado el retorno cooperativo también quede marginado de la materia imponible. Por el contrario, su carácter de ajuste de precio le hará correr el mismo tratamiento que se aplica a la operación de la cual proviene. Es decir que si esta fuera imponible, el retorno también lo será; pero si la 
operación estaba exenta o no alcanzada por el impuesto, del mismo modo deberá ser considerado su correspondiente retorno.

Por su parte, los intereses sobre las cuotas sociales que abonan las cooperativas a sus asociados, dentro de las previsiones legales y estatutarias que enmarcan la asignación de esta retribución al capital social, también han merecido encuadramiento de carácter general en el ámbito del impuesto - salvo el caso de las cooperativas de consumo o de trabajo-, ya que se encuentran incluidos como ganancias de la segunda categoría -rentas de capital-.

Vale decir que si la actividad que realizan los asociados con su cooperativa mejora sus ingresos por vía de retorno e intereses, ellos soportarán la carga impositiva pertinente como cualquier contribuyente. Empero, es el asociado como persona individual quien soporta un tratamiento fiscal igual al resto de los ciudadanos; no la cooperativa, que es una organización que los asociados utilizan instrumentalmente para su actividad conjunta sin que genere rédito imponible por sí misma. ${ }^{22}$

\section{Conclusión}

Los desarrollos expuestos en los parágrafos precedentes son razones para sostener que los excedentes de las cooperativas - conforme la legislación argentina- no constituyen materia sujeta al impuesto a las ganancias. Sin embargo, aunque después de un arduo debate parlamentario se logró a último momento evitar la aprobación del proyecto de reforma tributaria mencionado al comienzo, es previsible que las embestidas para gravar a las cooperativas con este tributo continúen. En efecto, ya en años anteriores, siguiendo las directivas del Fondo Monetario Internacional (FMI), los gobiernos intentaron eliminar la exención otorgada a las cooperativas - así como a otras entidades sin fines de lucro como las mutuales, las asociaciones y las fundaciones - alegando motivos de trato igualitario y eficiencia recaudatoria. El argumento de que no debe existir tratamiento privilegiado, sumado a las siempre crecientes necesidades fiscales, llevan a las cooperativas al permanente acoso tributario.

Las razones señaladas para pretender imponer el gravamen encuentran asidero teórico en la negación de toda diferencia entre las cooperativas y las sociedades

22 "Cabe señalar que esto no significa conceder a las cooperativas ningún tratamiento especial o de excepción sino, solamente, el que corresponde a su verdadera naturaleza. Los asociados no están exentos de este tributo y los resultados que hubieran percibido de la cooperativa deben ser incorporados a sus respectivos balances impositivos dentro del rubro correspondiente" (Cracogna, 2006, p. 35). 
La distribución de excedentes en la legislación argentina de cooperativas y sus implicancias tributarias

de capital. Al afirmarse que las cooperativas consisten solamente en una forma más dentro del catálogo de las sociedades comerciales, desaparece toda razón para otorgarles un tratamiento impositivo diferenciado; más aún, se torna imperativo considerarlas como a las demás, ya que de otra manera se violaría el pie de igualdad que exige la competencia. Este razonamiento, fundado en el desconocimiento -real o pretendido- de la genuina naturaleza de las cooperativas, va obviamente más allá de la cuestión tributaria y amenaza la propia subsistencia de la diferencia cooperativa, tanto desde el punto de vista legal como económico.

\section{Referencias}

Aguilar Rubio, M. (2015). Los principios cooperativos en la legislación tributaria. Revista Jurídica de Economía Social y Cooperativa, (27), pp. 373-400.

Alianza Cooperativa Internacional. Declaración sobre la identidad cooperativa. Aprobada en el Congreso del Centenario, Manchester, Inglaterra, 1995.

Althaus, A. A. (1977). Tratado de derecho cooperativo (2. ed.). Rosario: Zeus.

Cracogna, D. (s. f.). La distribución de los excedentes en las cooperativas. Derecho y contabilidad. Doctrina societaria y concursal, (259).

Cracogna, D. (1986). Estudios de derecho cooperativo. Buenos Aires: Intercoop.

Cracogna, D. (2004). O ato cooperativo na América Latina. En G. Krueger (coord.), Ato Cooperativo e seu adequado tratamento tributário. Belo Horizonte: Mandamentos Editora.

Cracogna, D. (2006). Comentarios a la ley de cooperativas (3. ${ }^{a}$ ed.). Buenos Aires: Intercoop.

Cracogna, D. (2012). El capital en las cooperativas y las NIIF. En E. Favier Dubois (dir.), Derecho contable aplicado. Buenos Aires: Editorial Errepar.

Cracogna, D. (2015a). Las cooperativas en el marco del Código Civil y Comercial. Derecho Comercial y de las Obligaciones, (273).

Cracogna, D. (2015b). Las cooperativas frente al concurso y la quiebra. Buenos Aires: Jurisprudencia Argentina. 
Farrés Cavagnaro, J., \& Menéndez A. J. (1987). Cooperativas. Ley 20.337 comentada, anotada y concordada. Buenos Aires: Depalma.

Federación Argentina de Consejos Profesionales de Ciencias Económicas (FACPCE), Resolución Técnica N. 24 (RT 24).

Holyoake, G. J. (2016). Historia de los pioneros de Rochdale (trad. Bernardo Delom). Buenos Aires: Intercoop.

Instituto Nacional de Asociativismo y Economía Social (INAES), Res. N. ${ }^{\circ}$ 177/83, 577/84 y 247/09. 